\title{
Evaluating the impact of the internationalisation of urban planning on Saudi Arabian cities
}

\author{
B. Alatni, M. Sibley \& L. Minuchin \\ Manchester School of Architecture, \\ School of Environment and Development, UK
}

\begin{abstract}
The Kingdom of Saudi Arabia (KSA) has experienced change in the development of urban planning codes, the most recent being the 2010 planning codes. Every urban planning regulation and code is devised to implement the overall urban design paradigm most suited to the city in question. For instance, the demand for modern urban facilities, coupled with the need for better transport networks around cities, has resulted in the shift from limited storey heights for buildings to more liberal, limitless storey heights. From the 1970s to date, the Saudi Arabian government has been engaging internationally acclaimed designers and planners, such as Forster and Partners International Designers, and Henning Larsen Architects of Denmark, to work with Saudi Arabian experts in respect of the 'internationalisation' of urban planning. The main driver for the paradigm shift in the urban planning processes has been the population growth and economic development. This entails an increase in the demand for a new generation of high-tech and knowledge-oriented industries in order to spread public services more evenly and broaden the scope and effectiveness of development policies among regions. Given the potential of such an urban planning strategy to influence both the current and future urban form, this research assesses the impact of internationalisation of urban planning on Saudi Arabian cities. It concludes that planners themselves are not sufficiently appreciative of the requirement for urban infrastructure that accompanies the new planning regulations.

Keywords: internationalisation, urban planning, urban form, sustainable urban centre, Saudi Arabia.
\end{abstract}




\section{Introduction}

It is nearly impossible to extrapolate the impact of the current planning codes on the Kingdom of Saudi Arabia's cities, mainly because the 2010 codes have only been put in practice by a very small number of international firms working with developers. However, based on the historical perspective, it can be argued that the KSA should anticipate known and unknown impacts on the urban form. The KSA government has participated in the development of the planning codes by instigating the modernisation of urban centres and engaging internationally acclaimed designers and planners (Al-Naim [1]) to work with Saudi Arabian experts in this internationalisation of the Kingdom's planning strategy. The outcome is a highly institutional approach to the codification of urban planning and development that has been led by the government (Al-Naim [1]) through appointing international firms.

This research is, therefore, aimed at evaluating the impact of the internationalisation of urban planning for Saudi Arabian Cities. It concludes that even though the current planning codes have been passed, their impact on urban planning processes and urban form has not been adequately understood by planners, especially in terms of urban form and the eventual demand for urban infrastructure that will come with the adherence to the planning regulations.

\section{Urban development of Saudi Arabia: an historical perspective}

For years, the KSA has been developing a strategy to engage professionals in the pursuance of genuine urban development that could maintain the traditional and Islamic elements of the urban form on one hand, but could be contemporary on the other hand (Saleh [2, pp. 93-112]). This means that there has been a topdown approach to the way government planning agencies have gone about the development of planning codes, as argued by Saleh [2, pp. 93-112]. With this approach, one could face problems because of a lack of information about the application of the codes and their impact. For example, Saleh [2, p. 93] observed that there are challenges within urban development strategies relating to the integration of "traditional systems of planning and institutionalised systems of planning," mainly because of the political slant assumed by the entire process. In architectural terms, it is naturally believed that the traditional Islamic built environment provides a precedent for any new practices pertinent to neighbourhood design in the Islamic Community (Saleh [3, pp. 515-529]; AlHemaidi [4]), but an examination of the development of urban areas within Islamic communities would seem to suggest that such a principle may not be agreed upon. Islamic cities try to emulate the traditional architectural attributes, while maintaining the capabilities of buildings to perform within the prevailing climatic conditions and without compromising the Islamic social-cultural norms of the community (Saleh [3, pp. 515-529]; Al-Hemaidi [4]). Saleh [3, p. 517] further argued that "negligence of cultural and climatic aspects in the planning or design of neighborhoods contributes to the likelihood that space will not work 
well in the articulation of functions and activities" because "historically, cultural and climatic requirements and the security of space in traditional settlements in the Arabian Peninsula have been strictly maintained by social rules". Having identified the deficiencies of some of the traditional urban planning strategies, the government has been attempting to deal with this complex issue by engaging international designers, municipal officials, commercial and residential developers, and manufacturers in the use of planning codes. It has not done this as 'rigidly' as one would assume, but rather, has done so as a means of including 'emblems' within their projects (Saleh [5]). To date there has been a lack of information concerning the effect of appointing international firms. Thus far, there has been a reported paucity of research to justify the idea that the urban development strategies deployed by the government through planning codes have had their intended results (Fan and Khattak [6]), mainly because such research would require a considerable length of time to reflect on the planning codes and how they have impacted the urban form.

\section{Internationalisation within the urban development of Saudi Arabia}

As far back as the 1970s, international firms, such as Doxiadis and CSET International, were engaged to develop master plans for urban and regional areas so that developers would conform. The newest appointments were made more recently, from 2003 to 2010 during the development of planning codes for sustainable urban centres. Some of the international firms that have worked on such plans include Forster and Partners International Designers, and Henning Larsen Architects of Denmark. The top-down strategy regarding urban planning has the potential to impact upon urban form now and in the future (UNDP [7]. For instance political drive is cardinal to the appointment of international consultants on the issues of urban planning. However, there has been no tangible analysis of the impact that institutionally- driven internationalisation could have on various facets of urban form (Al-Naim [1]). Since early 2000, there has been an emerging world-wide trend of using international firms that have global reputations for iconic designs (Douglas et al. [8]). This makes perfect business and marketing sense because the business world has become globalised. However, international influence on the development of cities has not always been welcome; rather, it has been associated with a clash between "globalization and localization processes, and the dichotomy between the cultural forces currently shaping the built environment, i.e., modern-traditional, IslamicWestern, and local-international, is the result of this tension" (Mahgoub [9, p. 505]). One of the main reasons for the clash is that while international designers intend to localise their work through a comprehensive appreciation of culture, social, and political values, it becomes nearly impossible to implement their work and localise it fully because there is no clear pattern to follow if a city is engaged in rapid development, as is the case with the Middle East (Mahgoub [9, pp. 505-519]; Wilson [10]). The result has been urban forms that are chaotic, lacking identity and a sense of place, as argued by Mahgoub [9, pp. 505-519], 
mainly because there is a weak synthesis between traditional designs and international paradigms in design.

\subsection{Competitive engagement versus 'institutional' appointments for international firms}

The global architectural market has two ways of operating: (i) one in which international firms are invited to compete in the local design competitions; and (ii) one in which government institutions are involved. The latter approach weighs heavily on government initiatives, while the former largely relies on the competitiveness of individual firms in the international market. This implies that the global engagement of international firms is not necessarily bilateral (Shen and Yang [11]). Regardless of the mode of engagement of the international firms, Sklair [12, pp. 485-500] reasons that the drive for iconic status as a sociocultural or politico-economic power has a huge impact on the design. By 'iconic architecture', Sklair [12, p. 485] means "buildings and spaces that (1) are famous among professional architects and/or the public at large and (2) have special symbolic/aesthetic significance attached to them". A good example has been the private engagement of architects to develop some of the iconic structures of the 2008 Chinese Olympic Games (Shen and Yang [11]). Where there are heavy institutional engagements of international firms, the emphasis in terms of the work to be performed usually encompasses wider development strategies, such as the "planning codes for the Kingdom of Saudi Arabia" as well as the development of sustainable urban centres in the Kingdom.

\subsection{Sustainable urban centres as a vehicle for internationalisation in the Kingdom of Saudi Arabia}

Since 2010, the main driver for the use of international firms in the development of urban planning codes has been the desire to promote sustainable cities. This generally implies that international organisations are engaged to develop planning codes that could - inter alia - promote sustainable cities. Ishii et al. [13, pp. 4888-4896] explained that regardless of the region, sustainability in planning codes mainly relates to energy-conserving technologies as well as to the ability to make cities more environmentally sustainable. They further explained that the level of sustainability achievable in each building is "strongly influenced by the city's form, building uses, and their density pattern" (Ishii et al. [13, p. 4888]). It can, therefore, be argued that the KSA could expect a similar pattern of sustainable construction if developers were able to follow the current building codes of 2010. Nevertheless, cities around the Middle East have demonstrated that while the planning codes may have been created with good intentions, the actual implementation of sustainable construction has been poor. For example, Wilson [10] reported on the ecologic complications of the city of Dubai, which were attributed to an accelerated programme of expansion and a top-down approach to urbanism, coupled with the construction of iconic megaprojects. This means that there is a political influence on the codification of the urban development process (Faulconbridge [14]). Therefore, this research study 
explores the impact that internationalisation has had on urban development in the Kingdom of Saudi Arabia.

\section{Research methodology}

The work herein forms part of the overall research, which is aimed at evaluating the impact of internationalisation on the planning codes in the KSA. Therefore, this paper forms the basis upon which primary information is to be sought; as a result, 'documentary analysis' is the ideal research methodology for the work at hand. Because of the lack of primary information from those firms that have been engaged in the development of the planning codes, it is imperative to undertake a documentary analysis as an optimal way of comparing the various national and urban development plans, coupled with their related planning codes and the resulting developments. Within documentary analysis, a quantitative and/or qualitative approach may be taken. Quantitative analysis is a systematised method of research using sampling or word counts, which are then statistically analysed. This type of analysis has the disadvantage that it misses phrases with mixed, contextual meanings, and it is not appropriate for the purposes of this paper.

The qualitative methods include conversation analysis, semiotics, interpretative analysis, content analysis, narrative theory, and grounded analysis (Bryman [15]; Robson [16]). The documentary analysis involved in this paper will rely on narrative theory and content analysis. Robson [16] refers to content analysis as "codified common sense, a refinement of ways that might be used by laypersons to describe and explain aspects of the world about them". Narrative theory adds layers of analysis regarding the document's author and primary audience (Barry and Elmes [17]). There are several advantages to documentary analysis as compared to other research methodologies. Firstly, it is unobtrusive and non-reactive (Robson [16]). It is also devoid of researcher input or influence, whereas other methods, such as interviews and questionnaires, may affect the research results through the wording of questions. Additionally, within the research undertaken for this paper, the documents must be regarded contextually, and the documentary methodology allows this. This is especially vital with regard to planning and policy documents because they are not written in a vacuum, but are part of an overall governmental strategic plan.

\section{Assessing the impact of internationalisation on urban planning of Saudi Arabian cities}

\subsection{Riyadh}

Riyadh has been developed according to international planning notions since the late 1960s, with three different international firms, namely (i) Doxiadis 1968, (ii) SCET 1980, and (iii) ADA 1990-Present, all participating in the city's evolution. Figure 1 shows the master plan for Riyadh in 1970, with a dotted line denoting the overall master plan. Using the information presented in the master 
plan (Figure 1), it can be reasoned that there is a high likelihood that the international firms engaged earlier were dealing with zonal urban planning on a grand scale. The drive, at this point in time, was not 'sustainability' per se; rather, it was to change the outlook of the city after the discovery of oil in the 1960s (Mubarak [18]). This approach, according to El Sheshtawy [19], radically changed the Saudi city's shape and structure, with the older dense low-rises giving way to modern, sprawling lower-density urban forms and high-rise megaproject urban development.

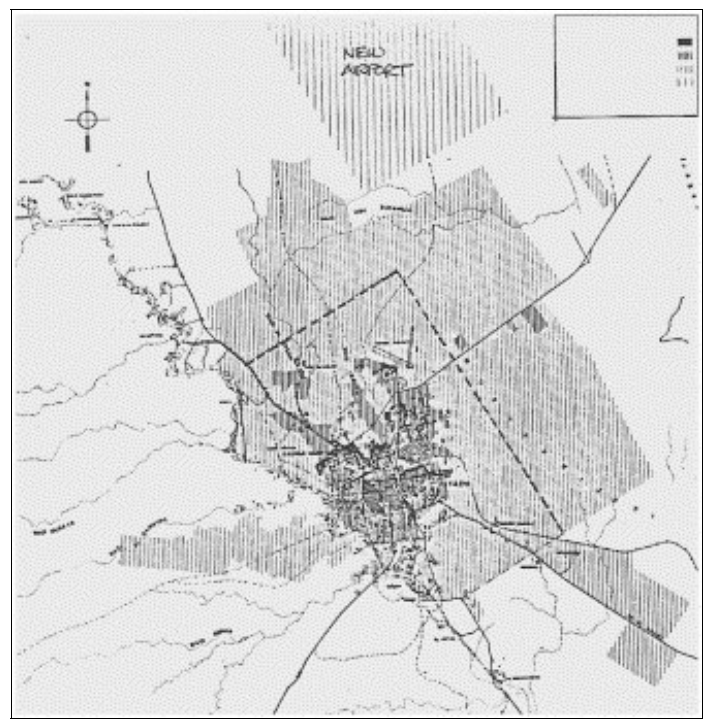

Figure 1: Doxiadis master plan of $300 \mathrm{~km} 2$ (dotted line) - (Source: Doxiadis, 1970).

When one looks at the city of Riyadh today, one perceives that although the urban planning pattern in old Riyadh was traditionally characterised by small and low-contour buildings, the traditional Islamic architecture was almost completely abandoned in the drive for modernisation.

The rejection of historic urban form traditional to the Arabic town, which had been the result of time-tested experimentation with methods to mitigate the hot, arid climate, in favour of Westernised urban designs is described by El Sheshtawy [20], as shown in Figure 2.

Taking Riyadh as an example, the Arriyadh Development Authority undertook research into similar developments being built in Paris, Shanghai, and Tokyo. However, factors such as differences in economics, demographics, social structures, and land availability have greatly limited the applicability of any lessons learned from such studies (ADA [21]).

The ADA [21] reports a situation in which the developers within Riyadh were using international cases and experiences in developing their final designs, as 


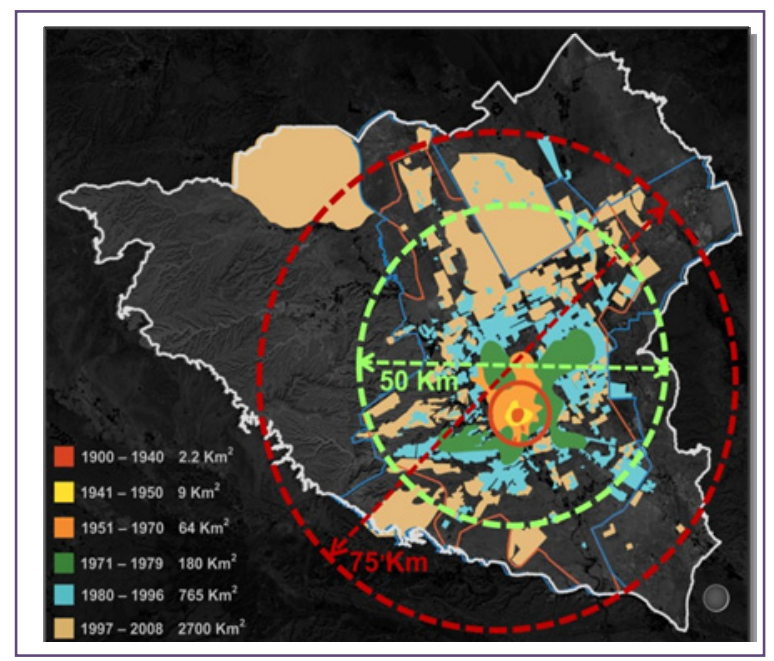

Figure 2: The Urbanisation process in Riyadh since 1900 (Source: MOMRA).

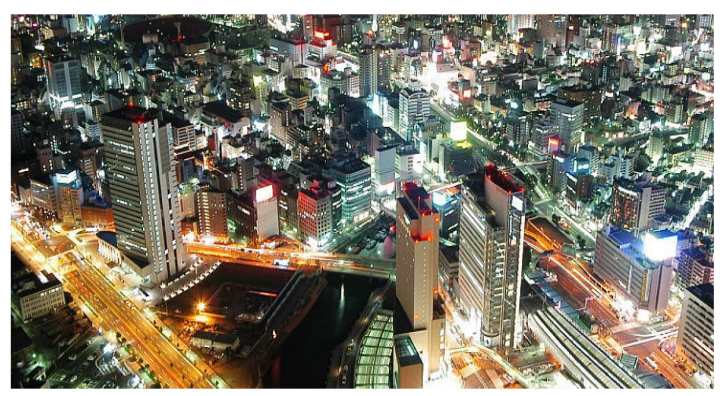

Tokyo-Japan

Figure 3: Comparative study of a global city by the Arriyadh Development Authority (2009).

shown in Figure 3. The result has been the total disappearance of the 'real Arab city', which has been associated with preconceptions, stereotypes, and a range of images, such as a city of mosques and minarets, slums, chaos, narrow streets, poverty, and now a haven for terrorists (El Sheshtawy [19]). On the contrary, the implementation of the planning codes that have been developed by international firms has resulted in a glamorous landscape with new skyscrapers, big shopping malls, and megaprojects. Neither of these views is truly representative of Arab cities (Saleh [22]), which were traditionally characterised by "simplicity, honesty of expression of architecture with exterior spaces reflecting the human scale and activity" (Saleh [23]). Cetin [24] also argues that the new urban areas in the KSA 
give a false impression of the evolution of Arab society, which appears to be disintegrated and disputed. The most current documentation reporting on the application of the urban planning codes is based on the development of the King Abdullah Financial District, developed partly by Henning-Larsen Architects, which appears to be a carefully planned and implemented project that would articulate the modernisation of a financial district

Henning Larsen [25] used a master plan to unite the Arabian urban traditions with the modern metropolis, giving the Saudi capital Riyadh a public open space and a characteristic skyline with a new outstanding landmark. During the building phase, Henning-Larsen Architects act as consultants, ensuring that the proposed scheme achieves a standard that will be seen as a world-class example of sustainable development. However, the sustainable aspect of the development is extremely weak because it focuses mainly on individual developers and how they fit into the overall master plan. Therefore, there has been an insignificant impact on sustainability, yet a huge shift in the urban form of Riyadh if one looks at the city from the 'Arabic city' standpoint.

\subsection{Dammam}

Dammam had a similar development sequence to Riyad, having experienced three major influences: (i) Candeliz Metra 1976, (ii) CH2M HILL 1980, and (iii) Abdul Hadi and Al Mo'aibed Engineering Consulting, who have worked from 2004 to the present. The city of Dammam hired Duany Plater-Zyberk and Company (DPZ), who created the smartcode in the USA to create a new code and regulations for the Central Business District in Dammam.

\section{Discussion}

Documentary analysis has indicated that as far as the Kingdom of Saudi Arabia is concerned, the number of international firms working in the country has been growing faster for the following reasons: (i) Some megaprojects are advertised as a competition in which the winner will design the megaproject; (ii) the local firms are not expanding sufficiently to tackle all the megaprojects at the same time, even though they are capable of designing them; (iii) the consultant firms are trying to perform a joint venture with international firms to increase their chances of getting the project and raising their profile; (iv) international firms are using international key drivers, such as sustainable design, to attract the institution to Saudi Arabia.

It has also been observed that while international firms may have developed new codes based on existing cities, there is a gap in the actual implementation of the planning codes. For example, Duany Plater-Zyberk and Company created the new code for the Dammam CBD. This is very similar to the Miami codes, which were created by them before they started in Dammam. However, the municipality of Dammam refused to adopt Miami-style planning codes because of the lack of implementation experience. 
Postmodern architecture and modern high-rise buildings are welcome in the culture of Saudi Arabia as a good example of modern city life, which encourages both public and private institutions to hire international firms. Nevertheless, it is a virtually inescapable truth that the actual implementation of sustainability is difficult to deduce from the documents, and the typical urban firm is more inclined to Western architecture and construction as opposed to traditional and/or Arabic architecture.

It has also been observed that commercial interests are key drivers of the engagement of international firms. For instance, Riyadh is influenced by the global phenomenon of 'marketecture,' a composite of 'market' and 'architecture (El Sheshtawy [19]). Before the turn of the century, there were few projects that indicated the move towards globalisation. Alfaysaliyyah Tower, completed in 2000 and designed by the British firm Foster and Partners, became a sign of a new era. The plan was to develop the entire area between Al'Ullaya Road and King Fahad Avenue as a new financial and administration centre. Another project was the Almamlka Tower, which was completed in 2003 and designed by Omrania and Associates in association with the American firm Ellerbe Becket.

\section{Conclusion}

Documentary analysis has demonstrated that the current urban planning codes have been passed with the help of international firms, but their implementation has been heavily skewed towards western architecture in an effort to modernise the cities examined. This includes the attraction of heavy service infrastructure to the cities in order to support the new lifestyles created within the business districts. However, there has been a poor use of internationalisation to positively influence the enhancement of urban forms that could be uniquely 'Arabic' and at the same time be highly sustainable, not only at the individual building level but also in terms of the overall urban form. This means that there is still a lack of knowledge of local culture among the Western firms that operate in Saudi Arabia and a lack of collaboration between Saudi and foreign architects. Using the topdown approach has not resolved the issue of incorporating Arabic-Islamic traditions into the development of urban planning codes. On the contrary, internationalisation has been instrumental in modernising the cities of Riyadh and Dammam, albeit in such a way that Western attributes of urban planning codes are more visible than traditional and/or Arabic-Islamic features. It could, therefore, be argued that there is an uncertain future in the urban planning codes because documentation shows that the appointing institutions are more likely to adopt Western architecture and technological solutions to such problems, with the need for sustainable facilities.

\subsection{Limitations of the research}

Without supporting primary data, documentary analysis is limited in that it cannot be used as a means to probe beyond the obvious factors associated with current developers' implementation of urban planning codes. As a result, there is 
a need to undertake a survey with stakeholders in urban form development (urban planners, industry, and international firms) to obtain their perceptions of the impact of internationalisation on urban form.

\section{References}

[1] Al-Naim, M.A., Riyadh: A City of 'Institutional' Architecture. The Evolving Arab City: Tradition, Modernity and Urban Development, Routledge, London: Ed: Elsheshtawy, Y., 2008.

[2] Saleh, M.A.E., Development versus Deterioration of Traditional Settlements of Southwest Saudi Arabia: Government Policies and Possible Courses of Action. Habitat International, 23(1), 1999.

[3] Saleh, E.A.M., The transformation of residential neighborhood: the emergence of new urbanism in Saudi Arabian culture. Building and Environment, 37, 2002.

[4] Al-Hemaidi, W.K., The metamorphosis of the urban fabric in Arab-Muslim City: Riyadh, Saudi Arabia. Journal of Housing and the Built Environment, 16(2), 179-201.2001.

[5] Saleh, M.A.E., The Changing Image of Arriyadh City: The Role of SocioCultural and Religious Traditions in Image Transformation. Cities, 18(5), pp. 315, 2001.

[6] Fan, Y. and Khattak, A. Does urban form matter in solo and joint activity engagement? Landscape and Urban Planning, Vol. 92(3-4), pp. 199-209, 2009.

[7] United Nations Development Program (2011) 28 August, 2010, Launch of Urban Planning Programme http://www.undp.org.sa

[8] Douglas, S.P., Samuel, C. \& Nijssen, E.J., Integrating Branding Strategy across Markets: Building International Brand Architecture. Journal of International Marketing, 9(2), pp. 97-114, 2001.

[9] Mahgoub, Y., Globalization and the built environment in Kuwait. Habitat International, 28, 2004.

[10] Wilson, M., Vertical Landscaping, a Big Regionalism for Dubai, International Journal of Urban and Regional Research, 34(4), December 2010, pp. 925-940, 2010.

[11] Shen, J. \& Yang J., Building Design In Beijing: Touching The Pulse Of Internationalization. Journal of Architectural and Planning Research, 28(1) (Spring), pp. 17-27, 2011.

[12] Sklair, L., The Transnational Capitalist Class and Contemporary Architecture in Globalizing Cities. International Journal of Urban and Regional Research, 29(3), September 2005, 2005.

[13] Ishii, S., Tabushi, S., Aramaki, T. \& Hanaki, K., Impact of future urban form on the potential to reduce greenhouse gas emissions from residential, commercial and public buildings in Utsunomiya, Japan. Energy Policy, 38, 2010 . 
[14] Faulconbridge, J.R., The Regulation of Design in Global Architecture Firms: Embedding and Emplacing Buildings. Urban Studies, 46(12), pp. 2537-2554, 2009.

[15] Bryman, A. Social Research Methods. Oxford, UK: Oxford University Press.2001.

[16] Robson, C. Real World Research, (2nd ed.). UK, USA: Blackwell publishing. 2002.

[17] Barry, D. \& Elmes, M. Strategy retold: Towards a narrative account of strategic discourse. Academy of Management Review, April. 1997.

[18] Mubarak, F., Urban growth boundary policy and residential suburbanization: Riyadh, Saudi Arabia. Habitat International, 28(4):567591. Planning Issues in the Middle East, 2004.

[19] El Sheshtawy, Y., The Evolving Arab City: Tradition, Modernity and Urban Development, Routledge, 2008.

[20] El Sheshtawy, Y., Redrawing Boundaries: Dubai, an Emerging Global City, in El Sheshtawy, Y. (ed.) Planning Middle Eastern Cities: An Urban Kaleidoscope in a Globalizing World. Routledge: London, 2004.

[21] ADA International Cases and Experiences as Arriyadh Development Authority (ADA), Riyadh's Metropolitan Sub-Centers Handbook, February, 2009, www.arriyadh.com

[22] Saleh, Mohamnmed A.E., The Integration of Tradition and Modernity: A Search for an Urban and Architectural Identity in Arriyadh, The Capital of Saudi Arabia, Habitat international Vol. 22, No.4, pp. 571-589, Elsevier Science Ltd. 1998.

[23] Saleh, M.A.E., The Changing Image of Arriyadh City: The Role of SocioCultural and Religious Traditions in Image Transformation. Cities, 18(5), pp. 315-330, 2001.

[24] Cetin M, Transformation and Perception of Urban Form in Arab City, International Journal of Civil \& Environmental Engineering IJCEE-IJENS Vol. 10 No: 04.2010.

[25] Henning Larsen Unpublished report for the "King Abdullah Financial District" By Henning Larsen Architects, Ed: Kurek, J., Associate, Architect, Riyadh, Saudi Arabia, 2010. 